\title{
Androgen receptors and serum testosterone levels identify different subsets of postmenopausal breast cancers
}

Giorgio Secreto ${ }^{1 *}$, Elisabetta Venturelli ${ }^{1}$, Elisabetta Meneghini ${ }^{2}$, Maria Luisa Carcangiu ${ }^{3}$, Biagio Paolini ${ }^{3}$, Roberto Agresti ${ }^{4}$, Cristina Pellitteri ${ }^{4}$, Franco Berrino ${ }^{1}$, Massimo Gion ${ }^{5}$, Patrizia Cogliati ${ }^{1}$, Giuseppina Saragò ${ }^{1}$ and Andrea Micheli ${ }^{6}$

\begin{abstract}
Background: Androgen receptors (AR) are frequently expressed in breast cancers, but their implication in cancer growth is still controversial. In the present study, we further investigated the role of the androgen/AR pathway in breast cancer development.

Methods: AR expression was evaluated by immunochemistry in a cohort of 528 postmenopausal breast cancer patients previously examined for the association of serum testosterone levels with patient and tumor characteristics. AR expression was classified according to the percentage of stained cells: AR-absent (0\%) and AR-poorly (1\%-30\%), AR-moderately (>30\%-60\%), and AR-highly (>60\%) positive.

Results: Statistical analysis was performed in 451 patients who experienced natural menopause. AR-high expression was significantly related with low histologic grade and estrogen receptor (ER)- and progesterone receptor (PR)-positive status ( $P$ trend $<0.001$ ). Mean testosterone levels were significantly higher in the AR-high category than in the other categories combined $(P=0.022)$, although a trend across the AR expression categories was not present. When women defined by ER status were analyzed separately, regression analysis in the ER-positive group showed a significant association of high testosterone levels with AR-highly-positive expression (OR 1.86; 95\% $\mathrm{Cl}, 1.10-3.16)$, but the association was essentially due to patients greater than or equal to 65 years $(\mathrm{OR} 2.42 ; 95 \% \mathrm{Cl}$, 1.22-4.82). In ER-positive group, elevated testosterone levels appeared also associated with AR-absent expression, although the small number of patients in this category limited the appearance of significant effects (OR 1.92; 95\% $\mathrm{Cl}, 0.73-5.02)$ : the association was present in both age groups ( $<65$ and $\geq 65$ years). In the ER-negative group, elevated testosterone levels were found associated (borderline significance) with AR-absent expression (OR 2.82, 95\% Cl, 0.98-8.06). In this ER-negative/AR-absent subset of tumors, elevated testosterone levels cannot stimulate cancer growth either directly or after conversion into estrogens, but they probably induce increased synthesis of some other substance that is responsible for cancer growth through binding to its specific receptor.

Conclusions: The findings in the present study confirm that testosterone levels are a marker of hormone-dependent breast cancer and suggest that the contemporary evaluation of ER status, AR expression, and circulating testosterone levels may identify different subsets of cancers whose growth may be influenced by androgens.
\end{abstract}

Keywords: Androgen receptors, Androgens, Postmenopausal breast cancer, Testosterone levels

\footnotetext{
* Correspondence: giorgio.secreto@istitutotumori.mi.it

'Department of Preventive and Predictive Medicine, Fondazione IRCCS

Istituto Nazionale dei Tumori, Milan, Italy

Full list of author information is available at the end of the article
} 


\section{Background}

Androgen receptors (AR) are expressed in more than $70 \%$ of primary breast cancers [1-11], in up to $90 \%$ of estrogen receptor (ER)-positive [5,7-12] and in about 50\% of ER-negative tumors [6-8,11]. AR positivity was found associated with favorable tumor characteristics, such as small tumor size, low histological grade, ER- and progesterone receptor (PR)-positive status [5-9,12], and with better outcomes than in patients with AR-negative tumors $[1,2,4,6,11,12]$. Such findings suggest that AR play a role in breast cancer development, but the clinical-pathological implication of the androgen/AR pathway on cancer growth is not yet well known.

We recently examined the relationships of serum testosterone levels with some tumor characteristics in a cohort of postmenopausal breast cancer patients and found that high levels of testosterone were significantly associated with the ER-positive status of tumors [13,14], a finding suggesting that serum testosterone levels are a marker of hormone-dependent breast cancer.

In the present study, we examined AR expression in tumors of the same cohort of postmenopausal patients in whom we had already measured testosterone levels. With the aim to further investigate the role of the androgen/AR pathway in breast cancer development, we evaluated the relationships of AR expression with testosterone levels, with age and body mass index (BMI) of patients and with selected tumor characteristics, both in the whole cohort and in age categories $(<65$ and $\geq 65$ years).

\section{Methods}

\section{Patients}

Of the 592 initial postmenopausal breast cancer women recruited in the TPM (testosterone, prognosis, mammary cancer) cohort, for 538 we had information on AR expression. Inclusion and exclusion criteria of the TPM cohort were extensively presented elsewhere $[13,14]$ and are here briefly summarized: all patients with primary breast cancer were treated surgically at the Breast Surgery Unit of the Fondazione IRCSS Istituto Nazionale Tumori, Milan (INT) from December 2003 to December 2006. Inclusion criterium was having histologically confirmed non-metastatic breast carcinoma (any $\mathrm{T}$, any $\mathrm{N}$, $\mathrm{M} 0$ ); exclusion criteria were nonepithelial cancer, a previous cancer diagnosis (except in situ cervical cancer or nonmelanoma skin cancer), and neoadjuvant chemotherapy or hormone therapy. The women provided a fasting blood sample before surgery; the blood samples were processed, divided into aliquots and stored at $-80^{\circ} \mathrm{C}$. Patient information and hormone receptor status (ER, PR, HER2) were extracted from the clinical records; collected data were entered into a specific database. Written informed consent was obtained from all included patients. The study was approved by the Scientific and Ethics Committee of the INT.

Of the 538 women with information on AR expression, 2 women aged 51-52 were excluded because they were not considered postmenopausal on the basis of their estradiol level (i.e., estradiol in serum was higher than $30 \mathrm{pg} / \mathrm{ml}$ ). Eight women were excluded because they proved to fall outside the recruitment criteria. Specifically, one was excluded because the date of the last menstruation was less than 1 year before the date of recruitment, and the other seven women were excluded because they had stopped hormone replacement therapy only 3 months before recruitment. Thus, 528 women were available for the present analysis.

Mean age at recruitment was 66.8 years (standard deviation 9.0, range 41-97). Four hundred and fifty-one women were going through natural (self-reported, nonsurgical) menopause (mean age, 66.6 \pm 8.8 ; range, 41-91); of the remaining 77 women, 42 had undergone hysterectomy, 32 had undergone bilateral ovariectomy, and 3, with uncertain self-reported information, were classified as missing status for menopause type. This crosssectional study is mainly addressed to those 451 naturally menopausal breast cancer patients. Analyses on all (natural and surgical) postmenopausal breast cancer patients are included in the Additional file 1.

\section{Testosterone assay}

Testosterone assay, already described elsewhere [14], was performed using RIA commercial kits (Orion Diagnostica, Espoo, Finland) according to the manufacturer's instructions. The coefficients of variation of measurement were $6.4 \%$ and $7.6 \%$ for mean testosterone titers of 0.359 and $0.455 \mathrm{ng} / \mathrm{ml}$, respectively.

\section{Androgen receptor assay}

AR expression was evaluated using tissue microarrays. Slides and paraffin blocks of 538 consecutive invasive breast cancers were retrieved from the archives of the department of pathology of the INT. All slides hematoxylin and eosin stained were reviewed by two pathologists, and the slide with the most representative tumor section was selected for each case. Three representative core tissue samples ( $1.5 \mathrm{~mm}$ in diameter) were taken from different areas of the invasive tumor and an additional one was from benign breast tissue, when present, and were assembled in 45 tissue microarray paraffin blocks using a Galileo TMA CK3500 Tissue Microarrayer. From each tissue microarray block, 4-mm-thick sections were cut and immunostained for monoclonal mouse anti-human androgen receptor, Dako (clone AR441, dilution 1:50) using Dako Autostainer. 


\section{Statistical methods}

ER and PR status were defined as negative when the percentage of stained tumor cells was $<10 \%$ and as positive for $\geq 10 \%$ of stained tumor cells, in accordance with published guidelines [15]. No guidelines have been published to define AR status. In most studies, the cutoff value of $10 \%$ of stained cells was used to separate AR-negative from AR-positive tumors $[5,8,9,16]$. Hu et al. [11] reported three groups of AR expression, negative $(0 \%$ of stained cells), low positive (1-10\%), and positive $(>10 \%)$, and Ogawa et al. [7] divided their patients in four groups according to AR expression, none, low $(<10 \%)$, intermediate $(10-50 \%)$, high $(>50 \%)$. In order to further analyze the association between AR and testosterone levels, we classified AR expression in four categories: AR-absent (0\%), AR-poorly ( $\geq 1 \%$ to $30 \%)$, AR-moderately ( $>30 \%$ to $60 \%$ ), and AR-highly $(>60 \%)$ positive. The cutoff of $1 \%$ was chosen because the association with testosterone levels became clearly visible, mainly in the ER-negative subset, when tumors with no cells stained for AR were separately considered. The cut offs of $60 \%$ and $30 \%$ were arbitrarily chosen to distinguish AR-high expression and divide the AR positive expression in groups with approximately equal numbers of patients. We did not further divide patients using the cutoff value of $10 \%$, commonly employed in other studies, because testosterone levels in the category $\geq 1 \%$ to $10 \%$ (61 patients, mean testosterone $0.396 \pm 0.182$ ) did not differ significantly from those in the category $>10 \%$ to $30 \%$ (50 patients, mean testosterone $0.373 \pm 0.194)(\mathrm{p}=0.409)$.

Differences in patient (age and BMI) and tumor characteristics (tumor size, histology, tumor grade, ER status, PR status, HER2 status and axillary involvement) between AR expression categories were investigated by the chi-square test for trend.

Testosterone circulating levels were square-root transformed, as the distribution of concentrations was not normal. Fisher's test was used to assess overall differences in mean testosterone levels by categories of AR expression, and linear contrasts were used for post-hoc comparisons of the high AR category versus absent, poor and moderate AR combined categories and of the absent AR category versus poor and moderate AR combined categories. In case of multiple comparisons, the Bonferroni method was used to adjust $P$ values. Trends across AR expression categories were tested by the nonparametric Cuzick test.

Logistic regression analysis was used to assess the ageadjusted association between testosterone and AR expression, and the age-adjusted odds ratios (OR) of being in a given AR expression category rather than in the reference category were estimated across testosterone tertiles. The ER status resulted as a determinant of the relationship between testosterone and AR expression. In particular, (a) in the ER-positive group, the frequency of women with low AR expression did not differ from that of women with moderate AR expression, thus the poor and moderate AR expression categories were pooled and used as reference category in estimating the age-adjusted OR of developing a tumor with absent or high AR expression versus one with the reference AR expression. (b) In the ER-negative group, there were no differences between low, moderate or high AR expression, so all three categories of positive AR expressions were pooled together and used as reference in a binomial logistic model estimating OR of having AR-absent instead of AR-positive tumors.

Testosterone tertiles were categorized according to the distribution of women in natural menopause. Although the likelihood ratio test did not reveal any significant interaction between age and testosterone, data were separately analyzed in order to take into account the hormonal pattern modification during years after the menopause in women $<65$ and those $\geq 65$ years of age.

Ninety-five percent confidence intervals $(95 \% \mathrm{CI})$ were estimated. Linear trends in OR were tested using ordinal variables of testosterone tertiles. All $P$ values refer to two-sided statistical tests; differences with $P \leq 0.05$ were considered significant. Analyses were performed with the Stata statistical package, 9.2 (2007) release (Stata Corporation, College Station, TX, USA).

\section{Results}

Of 528 postmenopausal women, 451 (85.4\%) were naturally menopausal and $74(14.0 \%)$ had had a surgical menopause (due to missing data on the type of menopause - natural or surgical, 3 other women were excluded). Compared to naturally menopausal women, those who had had surgical menopause were more frequently in the $\geq 65$ year age class $(64.9 \%$ vs. $53.7 \%$, $P=0.072)$, more frequently had a $B M I \geq 30 \mathrm{~kg} / \mathrm{m}^{2}(28.8 \%$ vs. $17.2 \%, P=0.026)$, more frequently had an ER-negative tumor $(24.3 \%$ vs. $15.8 \%, P=0.071)$, and more frequently had lower mean testosterone levels $(0.346 \pm 0.176$ vs. $0.418 \pm 0.196 \mathrm{ng} / \mathrm{ml}$, Fisher's $P=0.001)$. Furthermore, no association between AR expression and testosterone levels was found for women who had had surgical menopause [see Additional file 1, Table S2]. For this reason, we herein present results on naturally menopausal women only, and the results on all postmenopausal women are shown in the additional tables [see Additional file 1].

Table 1 shows frequencies of patients and tumor characteristics within categories of AR expression. About $13 \%$ of women in natural menopause had AR-absent tumors, $51 \%$ had tumors with poor or moderate AR expression, and $36 \%$ of women had tumors with AR-high 
Table 1 Androgen receptor (AR) expression and characteristics of breast cancer women in natural menopause

\begin{tabular}{|c|c|c|c|c|c|c|c|c|c|}
\hline & & & & AR e & ssion & & & & \\
\hline & & & & & & rate & & & \\
\hline & No. & $\%^{\mathbf{b}}$ & No. & $\%^{\mathbf{b}}$ & No. & $\%^{b}$ & No. & $\%^{b}$ & $P^{c}$ \\
\hline Age, yr & & & & & & & & & \\
\hline$<65$ & 29 & 49.2 & 55 & 49.1 & 57 & 47.5 & 68 & 42.5 & 0.259 \\
\hline$\geq 65$ & 30 & 50.8 & 57 & 50.9 & 63 & 52.5 & 92 & 57.5 & \\
\hline $\mathrm{BMl}, \mathrm{kg} / \mathrm{m}^{2}$ & & & & & & & & & \\
\hline$<25$ & 28 & 50.0 & 45 & 46.9 & 58 & 52.7 & 68 & 47.2 & 0.478 \\
\hline $25-30$ & 18 & 32.1 & 41 & 42.7 & 34 & 30.9 & 44 & 30.6 & \\
\hline$\geq 30$ & 10 & 17.9 & 10 & 10.4 & 18 & 16.4 & 32 & 22.2 & \\
\hline Tumor size, $\mathrm{cm}$ & & & & & & & & & \\
\hline$<2$ & 32 & 55.2 & 74 & 66.7 & 70 & 58.8 & 112 & 70.9 & 0.080 \\
\hline$\geq 2$ & 26 & 44.8 & 37 & 33.3 & 49 & 41.2 & 46 & 29.1 & \\
\hline Histology & & & & & & & & & \\
\hline Infiltrating ductal carcinoma (IDC) & 50 & 89.3 & 87 & 79.8 & 95 & 80.5 & 124 & 77.5 & 0.110 \\
\hline Other infiltrating carcinoma & 6 & 10.7 & 22 & 20.2 & 23 & 19.5 & 36 & 22.5 & \\
\hline Grade & & & & & & & & & \\
\hline$\leq 2$ & 22 & 37.9 & 68 & 61.3 & 72 & 61.5 & 112 & 70.4 & $<0.001$ \\
\hline$>2$ & 36 & 62.1 & 43 & 38.7 & 45 & 38.5 & 47 & 29.6 & \\
\hline Axillary nodal status & & & & & & & & & \\
\hline Negative & 34 & 60.7 & 66 & 60.6 & 74 & 62.7 & 95 & 60.1 & 0.958 \\
\hline Positive & 22 & 39.3 & 43 & 39.4 & 44 & 37.3 & 63 & 39.9 & \\
\hline ER status & & & & & & & & & \\
\hline Negative & 28 & 47.5 & 20 & 18.0 & 13 & 10.8 & 10 & 6.3 & $<0.001$ \\
\hline Positive & 31 & 52.5 & 91 & 82.0 & 107 & 89.2 & 149 & 93.7 & \\
\hline PR status & & & & & & & & & \\
\hline Negative & 34 & 57.6 & 42 & 38.2 & 37 & 30.8 & 36 & 22.6 & $<0.001$ \\
\hline Positive & 25 & 42.4 & 68 & 61.8 & 83 & 69.2 & 123 & 77.4 & \\
\hline HER2 status ${ }^{a}$ & & & & & & & & & \\
\hline Negative & 30 & 58.8 & 35 & 41.7 & 40 & 48.2 & 64 & 59.3 & 0.332 \\
\hline Positive & 21 & 41.2 & 49 & 58.3 & 43 & 51.8 & 44 & 40.7 & \\
\hline Total & 59 & $13.1^{d}$ & 112 & $24.8^{d}$ & 120 & $26.6^{d}$ & 160 & $35.5^{d}$ & \\
\hline
\end{tabular}

NOTES. Androgen receptor (AR) expression: absent, 0\%; poor, $\geq 1$ to $30 \%$; moderate, $>30$ to $60 \%$; high, $>60 \%$. Estrogen receptor (ER)-positive and Progesterone receptor (PR)-positive: $E R$ and $P R$ expression $\geq 10 \%$.

${ }^{a}$ One hundred and twenty-five (27.7\%) women had missing information about HER2 status.

${ }^{b}$ Column percentage. ${ }^{c}$ Chi-square test for trend. ${ }^{d}$ Row percentage.

expression (last row of Table 1). Tumors with high AR expression were slightly more frequent (not significantly) than tumors with lower AR expression in women aged $\geq$ 65 years (58\% vs. 51-53\%). Tumors with high AR expression were less frequently associated (not significantly) to the large tumor size $-\geq 2 \mathrm{~cm}-$ than tumors with ARabsent expression (29\% vs. $45 \%)$. The frequency of infiltrating ductal carcinoma decreased (not significantly) across increasing categories of AR expression (89\%, 80\%, $81 \%$, and $78 \%$ ). The frequency of tumors grade $\leq 2$ strongly increased across increasing AR expression (38\%, $61 \%, 62 \%$, and $70 \%)$ ( $P$ trend $<0.001$ ), as did the frequency of women with ER-positive or PR-positive tumors: $53 \%, 82 \%, 89 \%$, and $94 \%$ ( $P$ for trend $<0.001$ ), and $42 \%, 61 \%, 69 \%$, and $77 \%$ ( $P$ for trend $<0.001$ ), respectively. In the HER2-positive group, the incidence of women with poor and moderate AR expression tended to be higher than that of women with AR-absent or ARhigh expression (58\% and $52 \%$ vs. $41 \%$ ). In these naturally menopausal women, AR expression did not appear to be related to BMI or nodal status.

Mean testosterone levels by categories of AR expression are presented in Table 2. When all women in natural menopause were considered, the AR-high category 
Table 2 Serum testosterone by androgen and estrogen receptor expression in natural postmenopausal women with breast cancer

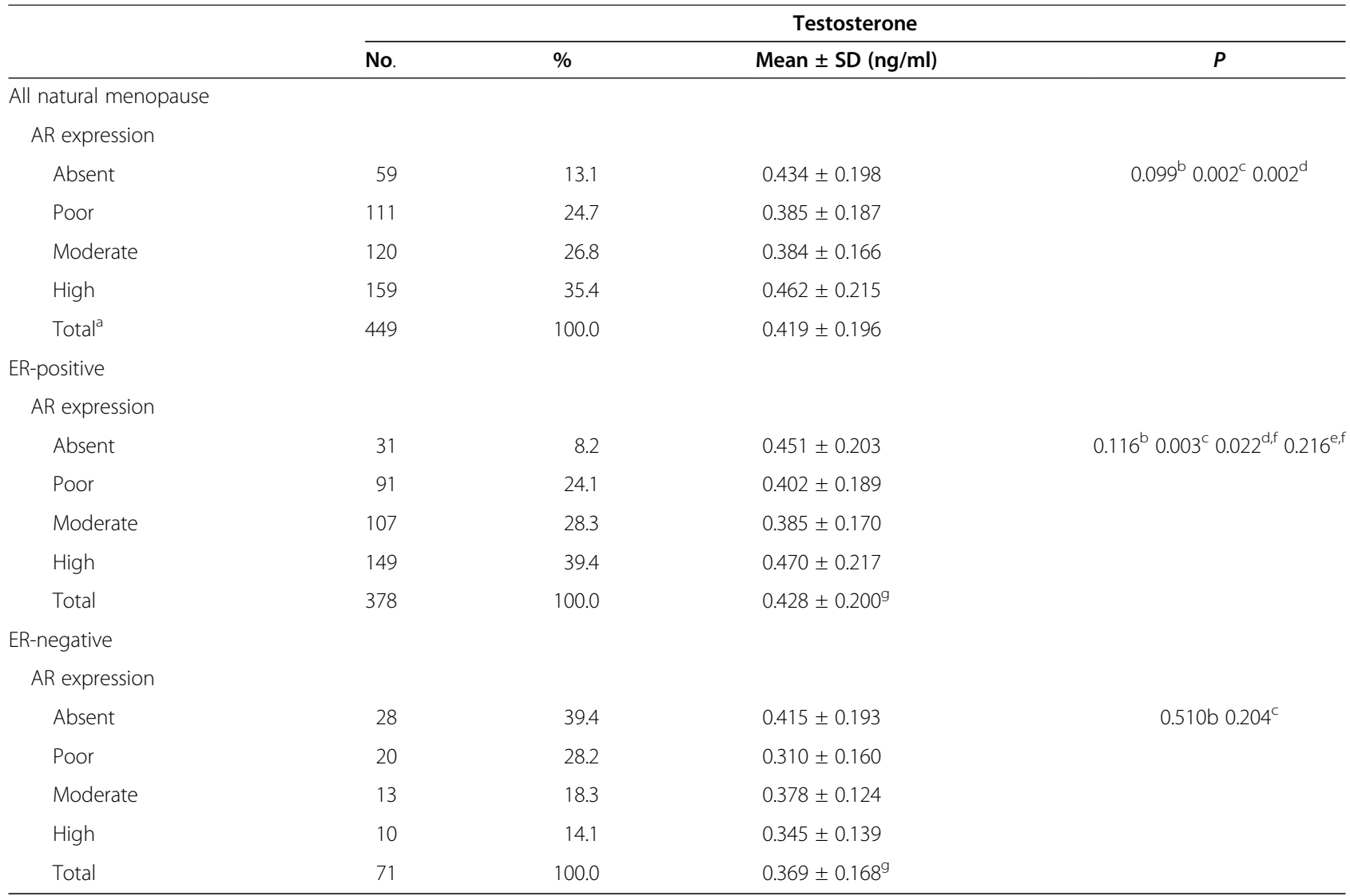

NOTES. Androgen receptor (AR) expression: absent, $0 \%$; poor, $\geq 1$ to $30 \%$; moderate, $>30$ to $60 \%$; high, $>60 \%$. Estrogen receptor (ER)-positive : ER expression $\geq 10 \%$.

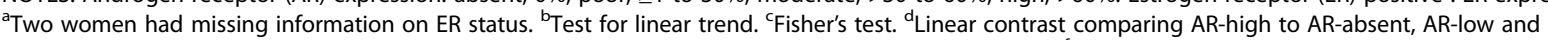
AR-moderate combined. ${ }^{\mathrm{e}}$ Linear contrast comparing AR-absent to AR-low and AR-moderate combined. ${ }^{\mathrm{f}}$ Bonferroni adjusted $P$ value. ${ }^{9} \mathrm{Fisher}$ 's test $P=0.023$.

showed the highest mean testosterone level, which was significantly different from that of the other categories combined (linear contrast: $P=0.002$ ), although a trend across the AR expression categories was not shown. When women defined by ER status were separately analyzed, those in the ER-negative group showed significantly lower mean testosterone levels than those in the ER-positive group $(0.369 \mathrm{ng} / \mathrm{ml}$ vs. $0.428 \mathrm{ng} / \mathrm{ml}$, Fisher's $P=0.023)$. In the ER-positive group, women with high AR expression had the highest testosterone level (linear contrast: Bonferroni adjusted $P=0.022$ ), yet women in the AR-absent category showed high testosterone levels, although not significantly different from those in low and moderate combined AR categories (linear contrast: Bonferroni adjusted $P=0.216)$. In the ER-negative group, women with AR-positive expressions had lower, not significantly, testosterone levels than women in the AR-absent category.

Logistic regression analysis further illustrated that ER-negative and ER-positive groups showed different age-adjusted relationships between testosterone and AR expression (Table 3). For women with ER-positive tumors, those in the highest testosterone tertile were significantly more likely to have high AR expression than women in the lowest tertile, with age-adjusted OR of 1.86 (95\% CI, 1.10-3.16) (Table 3). This association between high testosterone and high AR expression was essentially limited to women aged more than 65 years, with age-adjusted OR of 2.42 (95\% CI, 1.224.82). High testosterone was also associated to ARabsent tumors, however not significantly, although the low number in this category may limit the appearance of significant effects: the OR for the highest tertile was 1.92 (95\% CI, 0.73-5.02). This association between high testosterone and AR-absent tumors was present in both age groups with similar patterns (Table 3). Other interesting information was derived from analyses on the ER-negative tumors. In women with ERnegative tumors, high testosterone was not related to AR-high expression but only to AR-absent expression (with borderline significance). The age-adjusted OR of having AR-absent instead of AR-positive tumors, comparing the highest to the first and second pooled tertiles (the low number of women required to pool the 
Table 3 Odds ratios of AR expression by testosterone tertiles in natural postmenopausal women with ER-positive breast cancer

\begin{tabular}{|c|c|c|c|c|}
\hline & \multicolumn{4}{|c|}{ Testosterone tertiles, $\mathrm{ng} / \mathrm{ml}$} \\
\hline & $\leq 0.328$ & $0.328-0.474$ & $>0.474$ & $P$ trend \\
\hline \multicolumn{5}{|l|}{ All ages } \\
\hline \multicolumn{5}{|l|}{ AR expression } \\
\hline Absent / poor-moderate & $8 / 70$ & $11 / 73$ & $12 / 55$ & \\
\hline age-adjusted OR (95\% Cl) & 1 & $1.31(0.50-3.46)$ & $1.92(0.73-5.02)$ & 0.189 \\
\hline High / poor-moderate & $42 / 70$ & $45 / 73$ & $62 / 55$ & \\
\hline age-adjusted OR (95\% Cl) & 1 & $1.04(0.61-1.77)$ & $1.86(1.10-3.16)$ & 0.020 \\
\hline \multicolumn{5}{|l|}{$<65$ years } \\
\hline \multicolumn{5}{|l|}{ AR expression } \\
\hline Absent / poor-moderate & $3 / 27$ & $6 / 39$ & $5 / 25$ & \\
\hline age-adjusted OR (95\% Cl) & 1 & $1.38(0.32-6.05)$ & $2.03(0.43-9.63)$ & 0.374 \\
\hline High / poor-moderate & $18 / 27$ & $23 / 39$ & $21 / 25$ & \\
\hline age-adjusted OR (95\% Cl) & 1 & $0.88(0.40-1.95)$ & $1.26(0.55-2.91)$ & 0.582 \\
\hline \multicolumn{5}{|l|}{$\geq 65$ years } \\
\hline \multicolumn{5}{|l|}{ AR expression } \\
\hline Absent / poor-moderate & $5 / 43$ & $5 / 34$ & $7 / 30$ & \\
\hline age-adjusted OR (95\% Cl) & 1 & $1.25(0.33-4.70)$ & $2.00(0.58-6.90)$ & 0.282 \\
\hline High / poor-moderate & $24 / 43$ & $22 / 34$ & $41 / 30$ & \\
\hline age-adjusted OR (95\% Cl) & 1 & $1.13(0.54-2.37)$ & $2.42(1.22-4.82)$ & 0.011 \\
\hline
\end{tabular}

NOTES. Androgen receptor (AR) expression: absent, $0 \%$; poor, $\geq 1$ to $30 \%$; moderate, $>30$ to $60 \%$, high: $>60 \%$. Estrogen receptor (ER) -positive: ER expression $\geq 10 \%$.

data), was $2.82(95 \%$ CI, 0.98-8.06) (data not in Tables). The OR within the considered age groups could not be estimated because too few subjects were available, but the association appeared limited to women aged $\geq 65$ years. For older women, the ratio AR-absent/AR-positive tumors was $6 / 15$ in the first and second pooled tertiles and $7 / 2$ in the third testosterone tertile, whereas for younger women the ratio AR-absent/AR-positive tumors was $10 / 19$ in the first and second pooled tertiles and 5/7 in the third testosterone tertile.

\section{Discussion}

In the present study, we explored the role of $A R$ in breast cancer by evaluating relationships between AR expression, serum testosterone levels, and some patient (age, BMI) and tumor characteristics (size, nodal involvement, histology, grade, ER status, PR status, HER2 status) in a cohort of postmenopausal patients. The association of testosterone and AR expression was more evident in patients who experienced natural menopause than in the whole cohort, which included patients with surgical menopause (see Additional file 1, Table S3). We therefore focused our attention on patients in natural menopause. Our main finding was that elevated testosterone levels were associated with AR-highly-positive expression in ER-positive tumors (a highly significant relationship) but, surprisingly, elevated testosterone levels were also associated with AR-absent expression in ER-negative tumors (borderline significance). The strong relationship of testosterone and AR in ER-positive tumors was essentially due to patients $\geq 65$ years, which was responsible for the significant association found in the whole cohort. We also found that AR positivity was significantly related to low histological grade, ERpositive status and PR-positive status and was also associated, although not significantly, to small tumor size $(<2 \mathrm{~cm})$. The relationships of AR expression with age, BMI and HER2 status were weaker in naturally menopausal women and more evident in all postmenopausal women; and the association with axillary nodal status was virtually absent in both natural and all women groups (see Additional file 1, Table S1).

AR-positivity (poor, moderate, and high) was present in about $85 \%$ of tumors in our cohort, a percentage comparable to that of the other studies [5-10,16], which often regarded as AR-positive only those tumors with more than $10 \%$ of stained cells. Relationships of AR positivity with low grade, ER-positive and PR-positive status are well documented [5-10,16], and associations with tumor size and axillary nodal involvement have been reported in some studies $[7-9,11]$ but not in others $[8,10]$.

Our finding that AR are more frequently, although not significantly, expressed in older than in younger 
postmenopausal patients has also been reported in several other studies $[6,10,12]$. The association of AR expression with old age fits well with the previous finding on the same cohort that testosterone levels show a slight, not significant, increase in the oldest patients [13]. It is well known that the risk of developing breast cancer increases markedly with advancing age $[17,18]$, and signs of masculinization - markers of enhanced androgenic activity - are often present in aged women [19], suggesting a possible link between the androgen/ AR pathway and increased risk of breast cancer in an old age.

Our finding that elevated serum testosterone levels are significantly related with both ER-positivity [13] and AR-positivity suggests that an androgen excess may be not only a marker of hormone-dependence but that it may play a role in the development of these hormone-dependent tumors. The most plausible mechanism by which androgen excess stimulates growth of ER-positive/AR-positive cancers is increased conversion to estrogens, as suggested by the welldocumented finding of estradiol concentrations 10 times higher in tumor tissue than in blood [20-27] and by evidence of increased expression of estrogenproducing enzymes in breast cancer tissue [28-35], which is suggestive of local synthesis of estradiol from androgen precursors. Estradiol is therefore the final stimulator of breast epithelium proliferation, in agreement with the widely recognized role of estrogens in breast cancer. Increased expression of the androgenproducing enzyme $5 \alpha$-reductase is also well recognized in breast cancer tissue [29,32]: $5 \alpha$-reductase catalyzes the conversion of testosterone into the stronger and non-aromatizable dihydrotestosterone, thus explaining reports of dihydrotestosterone concentrations three times higher in tumor tissue than in blood [24,25]. Finally, testosterone and dihydrotestosterone probably up-regulate intratumor AR synthesis, which would account for the frequent co-existance of ER and AR in the same tumor.

Summing up our reasoning on hormone-dependent breast cancer growth, we suggest that most of the findings reported in the literature, including high intratumor concentrations of androgens and estrogens, elevated expression of estrogen-producing and androgen-producing enzymes, increased expression of ER and AR, can be explained by an androgen excess. Furthermore, looking at breast cancer growth under the viewpoint of the androgen excess, the elevated intratumor levels of androgens and estrogens should be regarded as two different sides of the same endocrine abnormality of the woman with cancer, i.e., an androgen excess, thus bypassing the problem of whether androgens inhibit or stimulate breast cancer growth.
In the present study, we regarded the AR-absent group as the negative group and classified the other tumors as poorly positive, moderately positive and highly positive according to the percentage of stained cells. The ARabsent group included about $13 \%$ of the patients in our cohort: it was characterized by high serum testosterone levels, comparable to those found in patients with highly positive-AR expression and substantially higher than those in poorly and in moderately AR-positive groups. About $47 \%$ of AR-absent tumors were also ER-negative, representing approximately $6 \%$ of the whole cohort. Our finding that elevated testosterone levels were associated with AR-absent expression in ER-negative tumors identified a particular subset of cancers whose growth may be stimulated by androgens. The positive association between testosterone and tumor size remained significant in this group: mean testosterone levels were $0.348 \pm 0.176$ for tumor size $<2 \mathrm{~cm}$ and $0.482 \pm 0.188$ for tumor size $\geq 2$ $\mathrm{cm}$ (Fisher's $P=0.043$ ). It is noteworthy that in women with ER-negative tumors the association between testosterone levels and AR expression substantially weakened and virtually disappeared when we classified as ARnegative those tumors with $\leq 10 \%$ or with $\leq 30 \%$ of stained cells, respectively. In the AR-absent/ER-negative subset, elevated androgen levels cannot stimulate cancer growth either directly or after conversion into estrogens, but they probably stimulate increased production of some other substance which is responsible for cancer growth through binding to its specific receptor. We suggest that such a substance may be the epidermal growth factor (EGF), whose synthesis and function is under the control of androgens [36] and whose receptor (EGFR or HER1) is expressed in 13-44\% of breast cancers [37-41] and in $6 \%$ of cases in a study by Barghava et al. [42], who used more stringent criteria in defining EGFR overexpression.

HER2 expression was examined in $70 \%$ of the tumors of our cohort. We did not find a significant association between HER2 and AR expression in the whole cohort, but when we divided women by ER status, HER2 overexpression showed a significant inverse relationship with AR-high expression in the ER-positive subset (women with HER2 overexpression were $36.0 \%$ in the AR-high group and $52.2 \%$ in the lower AR expression group, $P=0.007)$. In the ER-negative subset, HER2 overexpression was found significantly associated with AR positivity (women with HER2 overexpression were $82.9 \%$ in the AR-positive group and $29.2 \%$ in the AR-absent group, $P<0.001)$.

ER-negative/AR-positive tumors are regarded as the molecular apocrine subtype described by Farmer et al. [43], and the association between HER2 and AR has been repeatedly reported in these tumors [5,6,43-45]. Naderi et al. [45] demonstrated a functionally significant 
cross-talk between AR and HER2 in molecular apocrine tumors, whose growth is stimulated by androgens $[44,45]$.

We conclude our discussion with a brief comment about the protective role of androgens in breast cancer that has been postulated by several researchers on the basis of clinical evidence and preclinical studies [46,47]. Clinical evidence includes remission of metastases in 20$30 \%$ of patients treated with androgens at high doses; this is about the same remission rate of metastatic disease that is obtained with estrogens at high dosage. Preclinical studies on the role of androgens in breast cancer have been summarized in the review by Liao and Dickson [48]: in animals, androgens were mostly shown to inhibit cancer development and to favor regression of already established tumors in several studies, but in some experiments androgens were shown to enhance tumor growth. The same inconclusive results were obtained in cellculture studies, in which results were dependent on cell types and experimental conditions.

In healthy postmenopausal women, the totality of estrogens and large amounts of active androgens are synthesized in peripheral tissues from the adrenal precursor dehydroepiandrosterone (DHEA) [47,49-51]. A protective role in breast cancer has been suggested for DHEA and an increased risk of breast cancer has been attributed to the progressive decline in the production of the hormone with advancing age [47,49-51]. It has been calculated that postmenopausal ovaries contribute about $20 \%$ of circulating testosterone in healthy women, [47,51], but a much larger contribution may be expected from the ovaries of breast cancer patients. Ovarian androgen secretion is positively associated with the degree of ovarian stromal hyperplasia [Sluijmer et al. and Lucisano et al. as quoted by Labrie et al. 47], and our previous studies showed that interstitial cell hyperplasia is a typical feature of the ovaries of breast cancer patients with elevated testosterone levels [52,53]. Further evidence that the increased testosterone levels were of ovarian origin was provided by the significant reduction of testosterone excretion after oophorectomy $[54,55]$. As a final comment, the suggestion that an increased risk of breast cancer is associated to the progressive decrease in DHEA levels with age (adrenopause) contrasts with the evidence that high levels of adrenal androgen precursors are present in breast cancer tissue, a finding that implicates increased local production of active androgens and estrogens independently from the circulating levels of DHEA [21,23,56].

\section{Conclusions}

Summing up findings in the present study, we have shown that (a) relationships between AR expression and tumor characteristics are in agreement with reports in the literature; (b) the association with $\mathrm{AR}$ expression confirms testosterone levels as a marker of hormonedependent disease; (c) a subset of patients characterized by AR-absent expression and elevated levels of testosterone has been identified; and (d) the contemporary evaluation of ER status, AR expression, and circulating testosterone levels may identify different subsets of cancers whose growth may be influenced by androgens. These findings provide further support to the androgen excess theory of breast cancer, which points to androgen excess as a stimulatory hormonal alteration common to several breast cancer types, both ER-positive and ERnegative [57]. Breast cancer comprises a heterogeneous group of tumors that differ in clinical behavior, response to therapy, and outcome. Evidence exists that the androgen/AR pathway stimulates the growth of ER-negative/ AR-positive tumors and AR-targeted therapy has been proposed for the treatment of these tumors $[7,9,58]$. Findings of the present study suggest that the evaluation of serum testosterone levels may provide a better characterization of different subsets of breast cancer and may provide additional information on the role of the androgen/AR pathway in the regulation of breast cancer growth.

\section{Additional file}

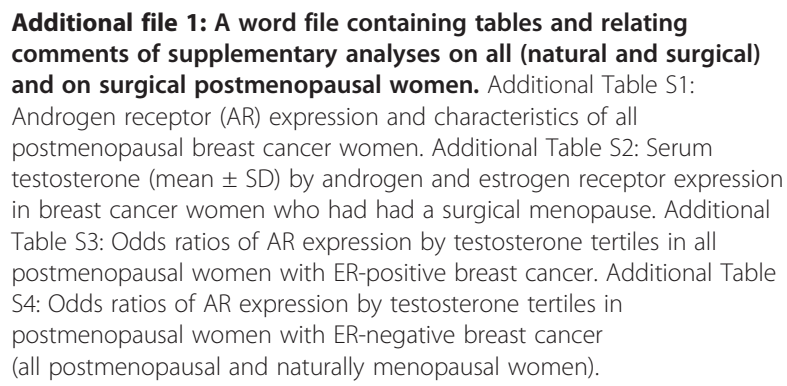

\section{Abbreviations}

AR: Androgen receptors; BMI: Body mass index;

DHEA: Dehydroepiandrosterone; EGF: Epidermal growth factor; EGFR: Human epidermal growth factor receptor; HER1: Human epidermal growth factor receptor 1; HER2: Human epidermal growth factor receptor 2; ER: Estrogen receptor; INT: Fondazione IRCSS Istituto Nazionale dei Tumori; 95\% $\mathrm{Cl}$ : Ninety-five percent confidence intervals; OR: Odds ratio; PR: Progesterone receptor; RIA: Radioimmunoassay; TPM: Testosterone, prognosis, mammary cancer.

\section{Competing interests}

The authors declare that they have no competing interests.

\section{Authors' contributions}

Giorgio Secreto and Andrea Micheli: conception and design of the study, interpretation of data and drafting of the manuscript. Elisabetta Meneghini: analysis and interpretation of data and drafting of the manuscript. Elisabetta Venturelli: acquisition and interpretation of data, and drafting of the manuscript. Maria Luisa Carcangiu and Biagio Paolini: evaluation of AR expression. Roberto Agresti, Patrizia Cogliati, Giuseppina Saragò, Cristina Pellitteri: acquisition of data. Franco Berrino and Massimo Gion: critical 
revision of the manuscript. All authors read and approved the final manuscript.

\section{Acknowledgements}

The authors thank Alberto Turco for assistance with data management and analysis, Betty Johnston for help with the English, and patients of the TPM cohort for their cooperation.

\section{Author details}

${ }^{1}$ Department of Preventive and Predictive Medicine, Fondazione IRCCS Istituto Nazionale dei Tumori, Milan, Italy. ${ }^{2}$ Descriptive Studies and Health Planning Unit, Fondazione IRCCS Istituto Nazionale dei Tumori, Milan, Italy. ${ }^{3}$ Department of Pathology, Fondazione IRCCS Istituto Nazionale dei Tumori, Milan, Italy. ${ }^{4}$ Breast Surgery Unit, Fondazione IRCCS Istituto Nazionale dei Tumori, Milan, Italy. ${ }^{5}$ Association for Application of Biotechnologies in Oncology and Center for the Study of Biological Markers of Malignancy, Regional Hospital, Local Health Unit (AULSS) No 12, Venice, Italy. ${ }^{6}$ Scientific Consultant for Scientific Direction and Descriptive Studies and Health Planning Unit, Fondazione IRCCS Istituto Nazionale dei Tumori, Milan, Italy.

Received: 27 August 2012 Accepted: 26 November 2012 Published: 14 December 2012

\section{References}

1. Søreide JA, Lea OA, Varhaug JE, Skarstein A, Kvinnsland S: Androgen receptors in operable breast cancer: relation to other steroid hormone receptors, correlations to prognostic factors and predictive value for effect of adjuvant tamoxifen treatment. Eur J Surg Oncol 1992, 18:112-118.

2. Isola JJ: Immunohistochemical demonstration of androgen receptor in breast cancer and its relationship to other prognostic factors. J Pathol 1993, 170:31-35.

3. Hall RE, Aspinall JO, Horsfall DJ, Birrell SN, Bentel JM, Sutherland RL, Tilley WD: Expression of the androgen receptor and an androgen-responsive protein, apolipoprotein D, in human breast cancer. Br J Cancer 1996, 74:1175-1180.

4. Kuenen-Boumeester $V$, Van der Kwast TH, Claassen CC, Look MP, Liem GS, Klijn JG, Henzen-Logmans SC: The clinical significance of androgen receptors in breast cancer and their relation to histological and cell biological parameters. Eur J Cancer 1996, 32A:1560-1565.

5. Moinfar F, Okcu M, Tsybrovskyy O, Regitnig P, Lax SF, Weybora W, Ratschek $M$, Tavassoli FA, Denk H: Androgen receptors frequently are expressed in breast carcinomas: potential relevance to new therapeutic strategies. Cancer 2003, 98:703-711.

6. Agoff SN, Swanson PE, Linden H, Hawes SE, Lawton TJ: Androgen receptor expression in estrogen receptor-negative breast ancer. Immunohistochemical, clinical, and prognostic associations. Am J Clin Pathol 2003, 120:725-731.

7. Ogawa Y, Hai E, Matsumoto K, Ikeda K, Tokunaga S, Nagahara H, Sakurai K, Inoue T, Nishiguchi Y: Androgen receptor expression in breast cancer: relationship with clinicopathological factors and biomarkers. Int J Clin Oncol 2008, 13:431-435.

8. Park S, Koo J, Park HS, Kim JH, Choi SY, Lee JH, Park BW, Lee KS: Expression of androgen receptors in primary breast cancer. Ann Oncol 2010, 21:488-492.

9. Niemeier LA, Dabbs DJ, Beriwal S, Striebel JM, Bhargava R: Androgen receptor in breast cancer: expression in estrogen receptor-positive tumors and in estrogen receptor-negative tumors with apocrine differentiation. Mod Pathol 2010, 23:205-212.

10. Yu Q, Niu Y, Liu N, Zhang JZ, Liu TJ, Zhang RJ, Wang SL, Ding XM, Xiao XQ: Expression of androgen receptor in breast cancer and its significance as a prognostic factor. Ann Oncol 2011, 22:1288-1294.

11. Hu R, Dawood S, Holmes MD, Collins LC, Schnitt SJ, Cole K, Marotti JD, Hankinson SE, Colditz GA, Tamimi RM: Androgen receptor expression and breast cancer survival in postmenopausal women. Clin Cancer Res 2011, 17:1867-1874

12. Gonzales-Angulo AM, Stemke-Hale K, Palla SL, Carey M, Agarwal R, MericBerstam F, Traina TA, Hudis C, Hortobagyi GN, Gerald WL, Mills GB, Hennessy BT: Androgen receptor levels and association with PIK3CA mutations and prognosis in breast cancer. Clin Cancer Res 2009, 15:2472-2478
13. Secreto $G$, Venturelli E, Meneghini E, Greco M, Ferraris C, Gion M, Zancan M, Fabricio AS, Berrino F, Cavalleri A, Micheli A: Testosterone and biological characteristics of breast cancers in postmenopausal women. Cancer Epidemiol Biomarkers Prev 2009, 18:2942-2948.

14. Secreto G, Meneghini E, Venturelli E, Cogliati P, Agresti R, Ferraris C, Gion M, Zancan M, Fabricio AS, Berrino F, Cavalleri A, Micheli A: Circulating sex hormones and tumor characteristics in postmenopausal breast cancer patients. A cross-sectional study. Int J Biol Markers 2011, 26:241-246.

15. Hammond ME, Hayes DF, Wolff AC, Mangu PB, Temin S: American society of clinical oncology/college of American pathologists guideline recommendations for immunohistochemical testing of estrogen and progesterone receptors in breast cancer. J Oncol Pract 2010, 6:195-197.

16. Micello D, Marando A, Sahnane N, Riva C, Capella C, Sessa F: Androgen receptor is frequently expressed in HER2-positive, ER/PR-negative breast cancers. Virchows Arch 2010, 457:467-476.

17. Denduluri N, Ershler WB: Aging biology and cancer. Semin Oncol 2004, 31:137-148.

18. Edwards BK, Howe HL, Ries LA, Thun MJ, Rosenberg HM, Yancik R, Wingo PA, Jemal A, Feigal EG: Annual report to the nation on the status of cancer, 1973-1999, featuring implications of age and aging on U.S. cancer burden. Cancer 2002, 94:2766-2792.

19. Kirschner MA: Hirsutism and virilism in women. Spec Top Endocrinol Metab 1984, 6:55-93.

20. van Landeghem AA, Poortman J, Nabuurs M, Thijssen JH: Endogenous concentration and subcellular distribution of estrogens in normal and malignant human breast tissue. Cancer Res 1985, 45:2900-2906.

21. Vermeulen A, Deslypere JP, Paridaens R, Leclercq G, Roy F, Heuson JC: Aromatase, 17beta-hydroxysteroid dehydrogenase and intratissular sex hormone concentrations in cancerous and normal glandular breast tissue in postmenopausal women. Eur J Cancer Clin Oncol 1986, 22:515-525

22. Santen RJ: Determinants of tissue oestradiol levels in human breast cancer. Cancer Surv 1986, 5:597-616.

23. Thijssen $\mathrm{JHH}$, Blankenstein MA: Endogenous oestrogens and androgens in normal and malignant endometrial and mammary tissues. Eur J Cancer Clin Oncol 1989, 25:1953-1959.

24. Mistry P, Griffiths K, Maynard PV: Endogenous C19-steroids and oestradiol levels in human primary breast tumour tissues and their correlation with androgen and oestrogen receptors. J Steroid Biochem 1986, 24:1117-1125.

25. Recchione C, Venturelli E, Manzari A, Cavalleri A, Martinetti A, Secreto G: Testosterone, dihydrotestosterone and oestradiol levels in postmenopausal breast cancer tissues. J Steroid Biochem Molec Biol 1995, 52:541-546.

26. Shibuya R, Suzuki T, Miki Y, Yoshida K, Moriya T, Ono K, Akahira J, Ishida T, Hirakawa $\mathrm{H}$, Evans DB, Sasano $\mathrm{H}$ : Intratumoral concentration of sex steroids and expression of sex steroid-producing enzymes in ductal carcinoma in situ of human breast. Endocr Relat Cancer 2008, 15:113-124.

27. Sasano H, Miki Y, Nagasaki S, Suzuki T: In situ estrogen production and its regulation in human breast carcinoma: from endocrinology to intracrinology. Pathol Int 2009, 59:777-789.

28. Bulun SE, Lin Z, Imir G, Amin S, Demura M, Yilmaz B, Martin R, Utsunomiya $H$, Thung S, Gurates B, Tamura M, Langoi D, Deb S: Regulation of aromatase expression in estrogen-responsive breast and uterine disease: from bench to treatment. Pharmacol Rev 2005, 57:359-383.

29. Suzuki T, Miki Y, Moriya T, Akahira J, Ishida T, Hirakawa H, Yamaguchi Y, Hayashi S, Sasano H: 5Alpha-reductase type 1 and aromatase in breast carcinoma as regulators of in situ androgen production. Int J Cancer 2007, 120:285-291.

30. Suzuki T, Miki Y, Akahira J, Moriya T, Ohuchi N, Sasano H: Aromatase in human breast carcinoma as a key regulator of intratumural sex steroid concentrations. Endocr J 2008, 55:455-463.

31. Santen RJ, Brodie H, Simpson ER, Siiteri PK, Brodie A: History of aromatase: saga of an important biological mediator and therapeutic target. Endocr Rev 2009, 30:343-375.

32. Suzuki T, Miki Y, Takagi K, Hirakawa H, Moriya T, Ohuchi N, Sasano H: Androgens in human breast carcinoma. Med Mol Morphol 2010, 43:75-81.

33. Suzuki $T$, Miki $Y$, Nakata $T$, Shiotsu $Y$, Akinaga $S$, Inoue $K$, Ishida T, Kimura M, Moriya T, Sasano H: Steroid sulfatase and estrogen sulfotransferase in normal human tissue and breast carcinoma. J Steroid Biochem Molec Biol 2003, 86:449-454 
34. Suzuki T, Nakata T, Miki Y, Kaneko C, Moriya T, Ishida T, Akinaga S, Hirakawa $\mathrm{H}$, Kimura M, Sasano H: Estrogen sulfotransferase and steroid sulfatase in human breast carcinoma. Cancer Res 2003, 63:2762-2770.

35. Nagasaki S, Miki Y, Akahira J, Suzuki T, Sasano H: 17beta-hydroxysteroid dehydrogenases in human breast cancer. Ann N Y Acad Sci 2009, 1155:25-32.

36. Pascall JC: Post-transcriptional regulation of gene expression by androgens: recent observations from the epidermal growth factor gene. $\mathrm{J}$ Mol Endocrinol 1997, 18:177-180.

37. Harris AL, Nicholson S, Sainsbury JR, Farndon J, Wright C: Epidermal growth factor receptors in breast cancer: association with early relapse and death, poor response to hormones and interactions with neu. J Steroid Biochem 1989, 34:123-131.

38. Bolla M, Chedin M, Souvignet C, Marron J, Arnould C, Chambaz E: Estimation of epidermal growth factor receptor in 177 breast cancers: correlation with prognostic factors. Breast Cancer Res Treat 1990, 16:97-102.

39. Toi M, Osaki A, Yamada H, Toge T: Epidermal growth factor receptor expression as a prognostic indicator in breast cancer. Eur J Cancer 1991, 27:977-980

40. Tsutsui S, Kataoka A, Ohno S, Murakami S, Kinoshita J, Hachitanda Y: Prognostic and predictive value of epidermal growth factor receptor in recurrent breast cancer. Clin Cancer Res 2002, 8:3454-3460.

41. Meche A, Cîmpean AM, Raica M: Immunohistochemical expression and significance of epidermal growth factor receptor (EGFR) in breast cancer. Romanian J Morphol Embryol 2009, 50:217-221.

42. Bhargava R, Gerald WL, Li AR, Pan Q, Lal P, Ladanyi M, Chen B: EGFR gene amplification in breast cancer: correlation with epidermal growth factor receptor mRNA and protein expression and HER-2 status and absence of EGFR-activating mutations. Mod Pathol 2005, 18:1027-1033.

43. Farmer $P$, Bonnefoi $H$, Becette $V$, Tubiana-Hulin $M$, Fumoleau $P$, Larsimont $D$, Macgrogan G, Bergh J, Cameron D, Goldstein D, Duss S, Nicoulaz AL, Brisken C, Fiche M, Delorenzi M, Iggo R: Identification of molecular apocrine breast tumours by microarray analysis. Oncogene 2005 , 24:4660-4671

44. Doane AS, Danso M, Lal P, Donaton M, Zhang L, Hudis C, Gerald WL: An estrogen receptor-negative breast cancer subset characterized by a hormonally regulated transcriptional program and response to androgen. Oncogene 2006, 25:3994-4008.

45. Naderi A, Hughes-Davies L: A functionally significant cross-talk between androgen receptor and ErbB2 pathways in estrogen receptor negative breast cancer. Neoplasia 2008, 10:542-548.

46. Dimitrakakis C, Zhou J, Wang J, Belanger A, Labrie F, Cheng C, Powell D, Bondy C: A physiologic role for testosterone in limiting estrogenic stimulation of the breast. Menopause 2003, 10:292-298.

47. Labrie F, Luu-The V, Labrie C, Bélanger A, Simard J, Lin SX, Pelletier G: Endocrine and intracrine sources of androgens in women: inhibition of breast cancer and other roles of androgens and their precursor dehydroepiandrosterone. Endocr Rev 2003, 24:152-182.

48. Liao DJ, Dickson RB: Roles of androgens in the development, growth, and carcinogenesis of the mammary gland. J Steroid Biochem Mol Biol 2002, 80:175-189.

49. Labrie F, Luu-The V, Bélanger A, Lin S-X, Simard J, Pelletier G, Labrie C: Is dehydroepiandrosterone a hormone? J Endocrinol 2005, 187:169-196.

50. Labrie F, Bélanger A, Bélanger P, Bérubé R, Martel C, Cusan L, Gomez J, Candas B, Chaussade V, Castiel I, Deloche C, Leclaire J: Metabolism of DHEA in postmenopausal women following percutaneous administration. J Steroid Biochem Mol Biol 2007, 103:178-188.

51. Labrie F, Martel C, Balser J: Wide distribution of the serum dehydroepiandrosterone and sex steroid levels in postmenopausal women: role of the ovary? Menopause 2011, 18:30-43.

52. Grattarola R: Androgens in breast cancer. I. Atypical endometrial hyperplasia and breast cancer in married premenopausal women. Am J Obstet Gynecol 1973, 116:423-428.

53. Grattarola R: Ovariectomy alone or in combination with dexamethasone in patients with advanced breast cancer and high levels of testosterone excretion. J Natl Cancer Inst 1976, 56:11-16.

54. Secreto G, Zumoff B: Paradoxical effects associated with supranormal urinary testosterone excretion in premenopausal women with breast cancer: increased risk of postmastectomy recurrence and higher remission rate after ovariectomy. Cancer Res 1983, 43:3408-3411.
55. Secreto G, Oriana S, Recchione C: variectomy alone or in combination with dexamethasone in patients with advanced breast cancer and high levels of testosterone or androstanediol secretion. Endocr Relat Cancer 1984, 14:55-58.

56. van Landeghem AA, Poortman J, Nabuurs M, Thijssen JH: Endogenous concentration and subcellular distribution of androgens in normal and malignant human breast tissue. Cancer Res 1985, 45:2907-2912.

57. Secreto G: Endocrine classification of postmenopausal breast cancers. In The Androgen-Excess Theory of Breast Cancer. Edited by Secreto G, Zumoff B. Trivandrum, Kerala, India: Research Signpost; 2012. http://www.trnres.com/ ebook.php.

58. Nahleh Z: Androgen receptor as a target for the treatment of hormone receptor-negative breast cancer: an unchartered territory. Future Oncol 2008, 4:15-21.

doi:10.1186/1471-2407-12-599

Cite this article as: Secreto et al.: Androgen receptors and serum testosterone levels identify different subsets of postmenopausal breast cancers. BMC Cancer 2012 12:599.

\section{Submit your next manuscript to BioMed Central and take full advantage of:}

- Convenient online submission

- Thorough peer review

- No space constraints or color figure charges

- Immediate publication on acceptance

- Inclusion in PubMed, CAS, Scopus and Google Scholar

- Research which is freely available for redistribution 